\title{
Assessment of Step and Touch Voltages for Different Multilayer Soil Models of Complex Grounding Grid
}

\author{
Srete Nikolovski, Goran Knežević, Zoran Baus \\ Department of Power Engineering, Faculty of Electrical Engineering, Osijek, Croatia
}

\begin{tabular}{l}
\hline \hline Article Info \\
\hline Article history: \\
Received Mar 26, 2016 \\
Revised May 18, 2016 \\
Accepted Jun 3, 2016 \\
\hline Keyword: \\
Computer Simulation \\
Ground Potential Rise \\
Grounding Grid \\
Safety Limits \\
Soil Resistivity Models \\
Step Voltage \\
Touch Voltage \\
\hline
\end{tabular}

\begin{abstract}
In this paper the influence of different soil models on step and touch voltages are presented. Soil resistivity is the basic characteristic of soil which affects a number of parameters (temperature, humidity, salt content). Basic methods of measuring soil resistivity presented in this paper are: Wenner method, Schlumberger method, General method, Driven rod (3-probe) method and the Dipole-Dipole method. Soil resistivity measurements are used to obtain an equivalent soil model (uniform model, two-layer horizontal model, multilayer horizontal model, vertical model and others). The CDEGS software package is used for computing GPR (Ground Potential Rise), touch and step voltage with several different soil models. The resulting effect of soil models on the grounding resistance, GPR at the surface, touch and step voltages are shown. The 3D spatial distribution and 2D presentation of all characteristic values for safety analysis are presented and plotted.
\end{abstract}

Copyright (C) 2016 Institute of Advanced Engineering and Science. All rights reserved.

\section{Corresponding Author:}

Srete Nikolovski,

Department of Power Engineering,

Faculty of Electrical Engineering, Josip Juraj Strossmayer University of Osijek,

K. Trpimira 2B, 31000 Osijek, Croatia.

Email: srete.nikolovski@etfos.hr

\section{INTRODUCTION}

The primary task of this paper is to show how different models of soil affect the calculation of the grounding. Grounding system is an important part of every power system, which is required to ensure proper operation of electrical equipment, ensure the users' security of these devices, and to take away short circuit currents or lightning [1]. To create a better model of the soil, it is necessary to know the characteristics of the soil. The most important characteristic of the soil is a specific soil resistivity, whose amount can be obtained by one of the techniques of measuring specific resistance [2],[3]. The completed model of the soil affects further the type and dimensions of the grounding and the depth to which it will be buried. Use of computer software for modeling and calculation of grounding has greatly facilitated and ensured more accurate models of soil and ground calculation compared to previously used empirical and graphical methods of soil modeling. CDEGS (Current Distribution, Electromagnetic Fields, Grounding and Soil Structure Analysis) is software package composed of eight different modules that offer a complete grounding analysis [4].

When grounding an object (power plants, substations, transmission lines, networks, etc.), the assumption is that the soil is a good conductor and that the current will freely flow through it. However, this may not be so, as the conductors of different materials are characterized by different specific resistances and the same happens with the ground. So, like any conductor, the soil in electrical terms is characterized by resistance which provides the passage of current. The resistance of the soil can be defined as the resistance between the opposite sides of the cube floor with a length of one meter site. The general soil resistivity is 
very high compared with the specific resistance of classic metal conductors. For different soil types, specific resistivity takes the value of several ohm-meters to several thousand ohm-meters.

\section{MAIN CHARACTERISTICS OF SOIL}

When grounding an object (power plants, substations, transmission lines, networks, etc.), the assumption is that the soil is a good conductor and that the current will freely flow through it. However, this may not be so, as the conductors of different materials are characterized by different specific resistances and the same happens with the ground. So, like any conductor, the soil in electrical terms is characterized by resistance which provides the passage of current. The resistance of the soil can be defined as the resistance between the opposite sides of the cube floor with a length of one meter site. The general soil resistivity is very high compared with the specific resistance of classic metal conductors. For different soil types, specific resistivity takes the value of several ohm-meters to several thousand ohm-meters. Figure 1 shows how specific soil resistivity changes depending on the percentage change in the content of moisture, salt and different temperatures [2].

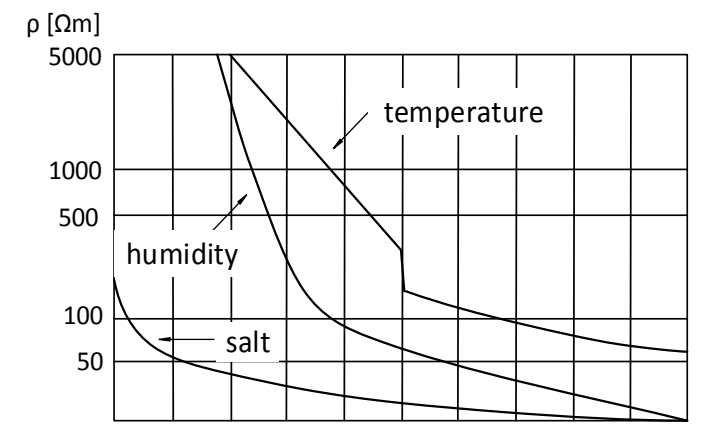

\begin{tabular}{|c|c|c|c|c|c|c|c|c|c|c|c|}
\hline \multirow{2}{*}{\multicolumn{2}{|c|}{ salt }} & 2 & 3 & 4 & 5 & 6 & 7 & 8 & 9 & 10 & $\%$ \\
\hline & & 5 & 10 & 15 & 20 & 25 & 30 & 35 & 40 & 45 & $\%$ \\
\hline & & & -1 & -10 & -5 & 0 & +5 & +1 & +15 & +20 & \\
\hline
\end{tabular}

Figure 1. Dependence of soil resistivity $\rho$ on the percentage of moisture, salt and temperature [2]

Also the frequency can have the influence on soil properties and the grounding impedance which is presented in [5].

\section{TECHNIQUES OF MEASURING SPECIFIC SOIL RESISTIVITY}

Measurement of specific soil resistivity is performed in such a way that the current is let go through two outer probes, current probes, while on the two probes which are in the same direction located between them, the voltage (potential) probes, the amount of voltage is measured [6]. Based on the released current and measured voltage, using Ohm's law, the resistance value is calculated, and, depending on the geometry of the method used to measure, the value of the apparent specific soil resistivity in Ohm - meters is calculated. In Figure 2 - Figure 6 different methods of soil resistance measurement are shown. Wenner's method of measuring specific ground resistance is presented in Figure 2. Schlumberger's method of measuring specific ground resistance is presented in Figure 3. 


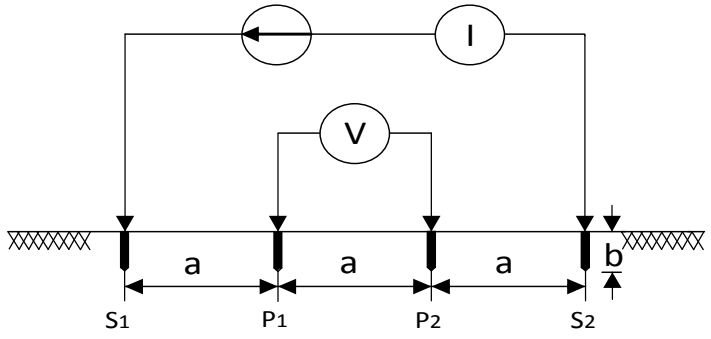

Figure 2. Wenner's method of measuring specific resistance

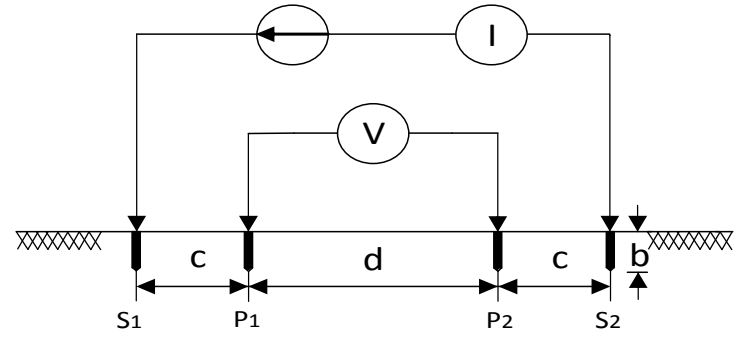

Figure 3. Schlumberger's method of measuring specific resistance

General method of measuring specific ground resistance is presented in Figure 4 and Dipol-Dipol method of measuring specific ground resistance is presented in Figure 5.

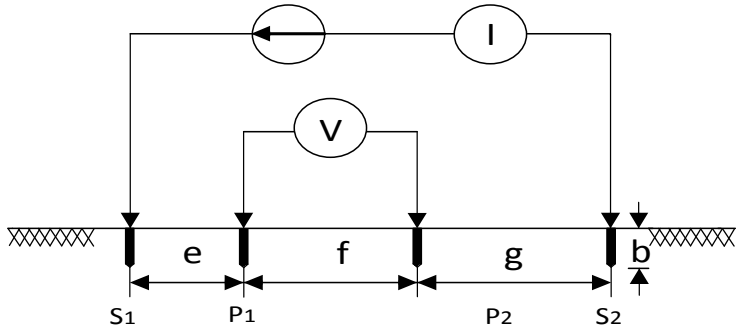

Figure 4. General method of measuring specific resistance

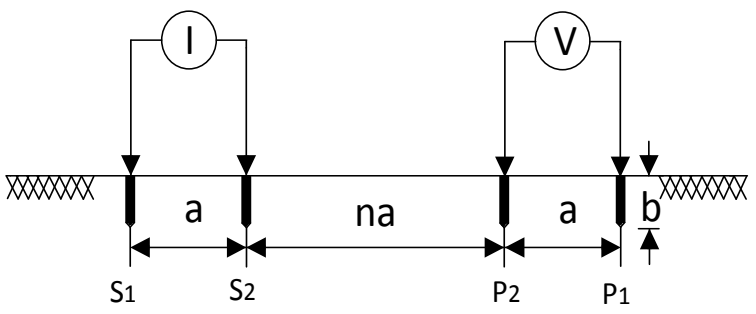

Figure 5. Dipol-Dipol method of measuring specific resistance

3-Probe method of measuring specific ground resistance is presented in Figure 6. The main difference from previously elaborated methods is that in this method instead of 4 probes only 3 probes are used for determining the ground resistance.

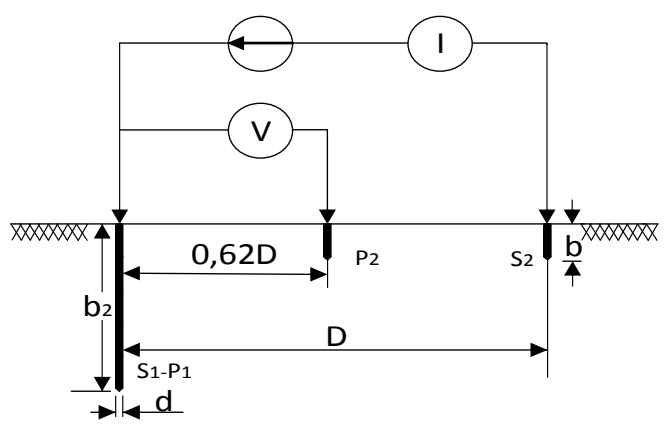

Figure 6. 3 Probe method of measuring specific ground resistance

\section{SOIL MODELS}

Interpretation and development of adequate model of the soil based on the measured values of the apparent specific soil resistivity is one of the most challenging parts after performing measurements. In practice, the soil is usually modeled as a single layer (uniform), or as a two-layer and horizontal in relation to the surface of the soil. In more complex configurations, it is necessary to use horizontal multi-layer soil model [6],[7]. There may be special configurations of the soil, for example, when there is an exponential change in specific soil resistivity, vertical stratification, and regular or irregular volumes of soil with different specific resistance of the surrounding soil. However, such configurations are very rare in practice and usually installation of grounding in such soil tends to be avoided. 


\subsection{Single layer-unuform soil modell} resistance.

Single-layer soil model (Figure 7) approximates the ground as homogeneous, that is, of constant

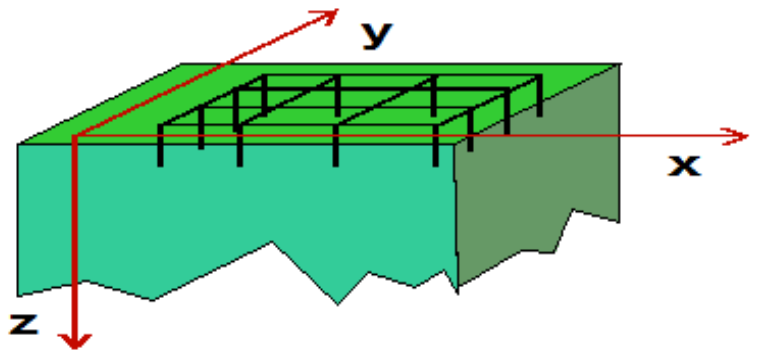

Figure 7. Single-layer soil model

Such model of soil is justified to be used when it is established by measurements that the apparent resistance of the soil does not vary significantly with increasing depth of measuring, or if it is not about a minor grounding system, so that certain omissions and approximations are allowed. An approximated single model of soil, or its resistance, can be obtained by taking the mean of all the measured apparent soil resistances, as shown in (1).

$$
\rho=\frac{\rho_{a(1)}+\rho_{a(2)}+\rho_{a(3)}+\ldots+\rho_{a(n)}}{n}
$$

where the numerator represents the sum of the apparent resistances on different distances and the denominator represents the total number of measurements. Another method for determining the resistance of a single-layer soil is according to (2).

$$
\rho=\frac{\rho_{\max }+\rho_{\min }}{2}
$$

where $\boldsymbol{\rho}_{\max }$ is the maximum apparent resistance measured $(\Omega \mathrm{m})$, and $\boldsymbol{\rho}_{\min }$ the minimum apparent resistance measured $(\Omega \mathrm{m})$.

\subsection{Two-layer model of horizontal soil}

Two-layer soil model consists of the upper layer of the final depth $h$ and the specific $\rho_{l}$ resistance and the lower layer of infinite depth and specific resistance $\rho_{2}$, [8],[9] Figure 8.

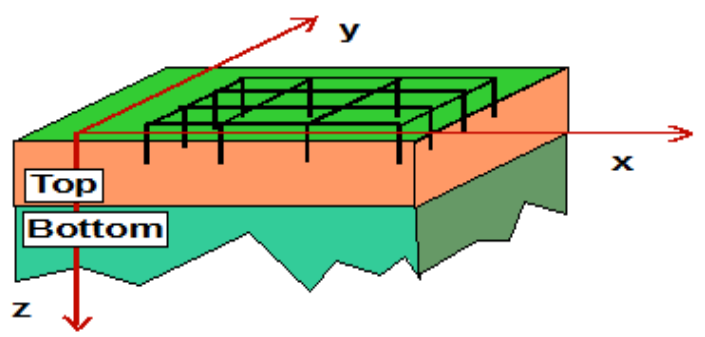

Figure 8. Two-layer horizontal model

The difficulty in using this model is a mathematical determination of the depth of the first layer due to variations in the structure and properties of the soil. Methods used to determine the parameters of twolayer horizontal soil $\left(\rho_{1}, \rho_{2}, h\right)$ on the basis of measuring specific soil resistivity can be classified into two 
groups: empirical and analytical. Determination of the parameters of the horizontal two-layer soil is analytically made by applying mathematical formulas and functions (3), (4) and (5).

$$
\begin{aligned}
& \rho_{a}=\rho_{1} \cdot\left\{1+4 \sum_{n=1}^{\infty} K^{n}\left[\frac{1}{\sqrt{1+\left(\frac{2 \cdot n \cdot h}{a}\right)^{2}}}-\frac{1}{\sqrt{4+\left(\frac{2 \cdot n \cdot h}{a}\right)^{2}}}\right]\right\} \\
& K=\frac{\rho_{2}-\rho_{1}}{\rho_{2}+\rho_{1}} \\
& f\left(\rho_{1}, \rho_{2}, h\right)=\sum_{i=1}^{N}\left[\frac{\left(\rho_{m i}-\rho(i)\right)^{2}}{\rho_{m i}^{2}}\right]
\end{aligned}
$$

where $K$ is the reflection coefficient, $\boldsymbol{\rho}_{\boldsymbol{m} i}$ measured value of specific soil resistivity and $\boldsymbol{\rho}_{(i)}$ an estimated value of specific resistance of the soil.

Another way of parameter determination is by using Sunde's graphical method (Figure 9), which can roughly estimate the parameters of the two-layer horizontal soil without the use of computer or sophisticated equations.

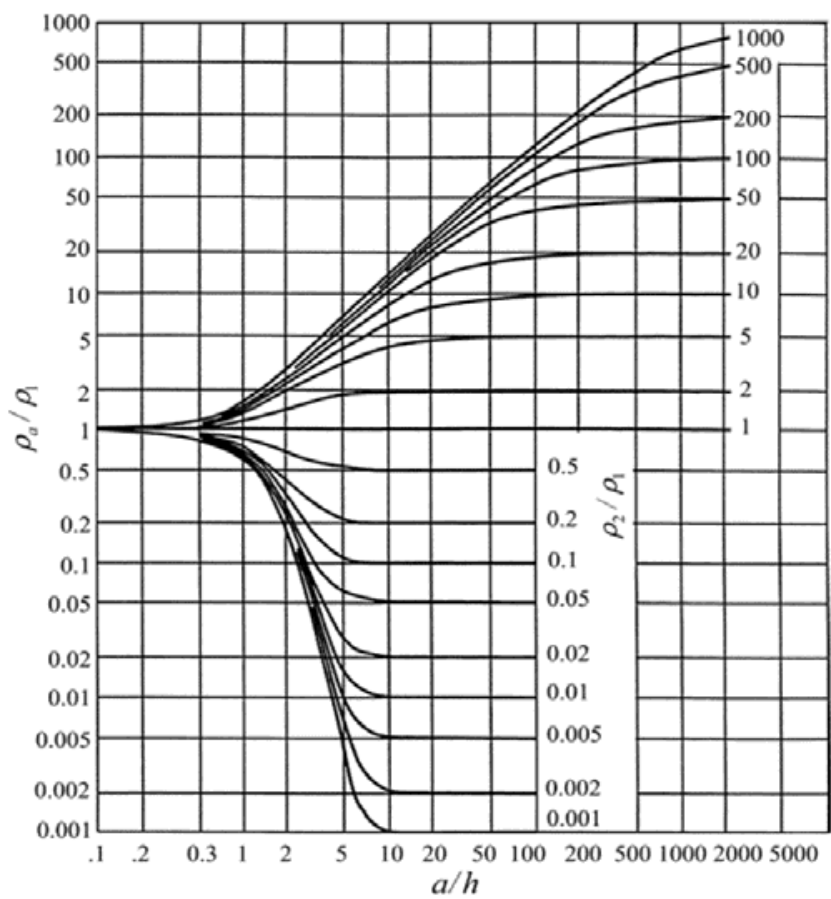

Figure 9. Sunde's curves for determining parameters of two-layer horizontal soil [10]

\subsection{Three-layer model of horizontal soil}

Horizontal three-layer ground model is shown in Figure 10. In this case, the soil consists of 3 layers, where each layer is characterized by the accompanying specific resistance and thickness of the layer until the last $3^{\text {th }}$, which is of an infinite thickness. [4], Determining parameters of multi-layer models requires the use of computer programs and advanced mathematical functions (complex figure methods, advanced integrated Taylor's and Simpson's formulas) because the calculation in relation to the single or two layer soil model becomes significantly complicated. The other two most common models of soil that occur in reality are vertical (Figure 11) two-layer or multi-layer soil model and the soil model in which the specific soil resistivity changes exponentially with depth. 


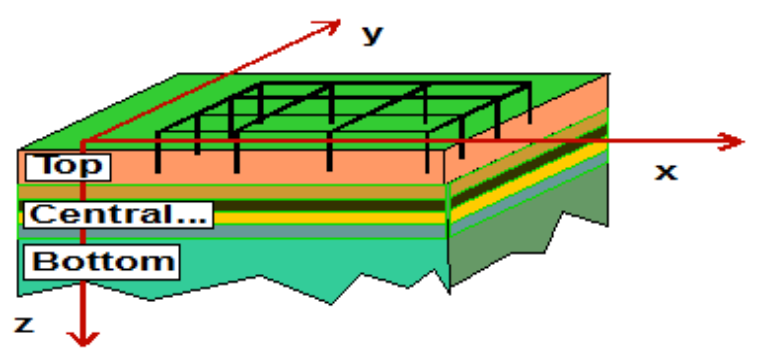

Figure 10. Three-layer soil model

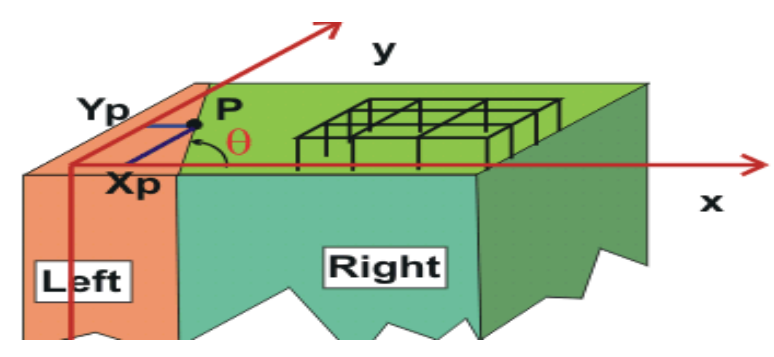

Figure 11. Two-layer vertical soil model

After determining the apparent specific resistivity of each vertically oriented layer, $\rho_{l}, \rho_{2}$, the equivalent specific resistance, $\rho_{e}$, of the adjacent vertical tiers can be determined (6) [9].

$$
\rho_{e}=\frac{S \cdot \rho_{1} \cdot \rho_{2}}{S_{1} \cdot \rho_{2}+S_{2} \cdot \rho_{1}}
$$

Soil with an exponential change in specific soil resistivity with depth is determined by the specific resistance on the surface, $\rho_{l}$, specific resistance of the deepest part, $\rho_{2}$, and the coefficient $\lambda$. The apparent specific resistivity, $\rho_{a}$, for such soil and Wenner's way of measurement is calculated according to (7).

$$
\rho_{a}=\rho_{2}-\left(\rho_{2}-\rho_{1}\right) \cdot e^{-\lambda a} \cdot\left(2-e^{-\lambda a}\right)
$$

\section{SIMULATION OF THE INFLUENCE OF DIFFERENT SOIL MODELS ON GROUNDING SYSTEM PERFORMANCE}

Software package CDEGS is a collection of integrated engineering software tools for accurately analyzing problems involving grounding, electromagnetic fields, electromagnetic interferences, and various aspects of cathodic protection. CDEGS software package nowadays consists of eight engineering modules, and in this study the following two are used: RESAP and MALT. RESAP module is used to determine the equivalent model of the soil based on the selection of the measuring method and the measuring values of the apparent resistivity (or resistance) of the soil. MALT module is used for the analysis of low frequency grounding [4]. Modeling of the soil was performed in RESAP module. Measurements done by Wenner's four probe method are entered in RESAP module. In the selection of soil types that is to be modeled on the basis of the measurements is selected. In the first case, the soil is modeled as a single-layer, in the second case, the soil is modeled as horizontal two-layer and in third case as horizontal three-layer. Results for all three cases are presented in Figure 12, Figure 13 and Figure 14. For measurement of soil resistivity were used data from [11].

Table 1. Measurements of soil resistivity using Wenner's method [11]

\begin{tabular}{ccc}
\hline Time & Spacing (a) $[\mathrm{m}]$ & $\begin{array}{c}\text { Measured resistivity } \\
\rho[\Omega \mathrm{m})\end{array}$ \\
\hline 1 & 1 & 125.0354 \\
2 & 1.5 & 108.6677 \\
3 & 2 & 85.3257 \\
4 & 2.5 & 69.4292 \\
5 & 3 & 55.4177 \\
6 & 4 & 37.4478 \\
7 & 5 & 30.7876 \\
8 & 6 & 26.0124 \\
9 & 7 & 22.8708 \\
10 & 8 & 16.0850 \\
11 & 9 & 17.5301 \\
12 & 10 & 16.3364 \\
\hline
\end{tabular}




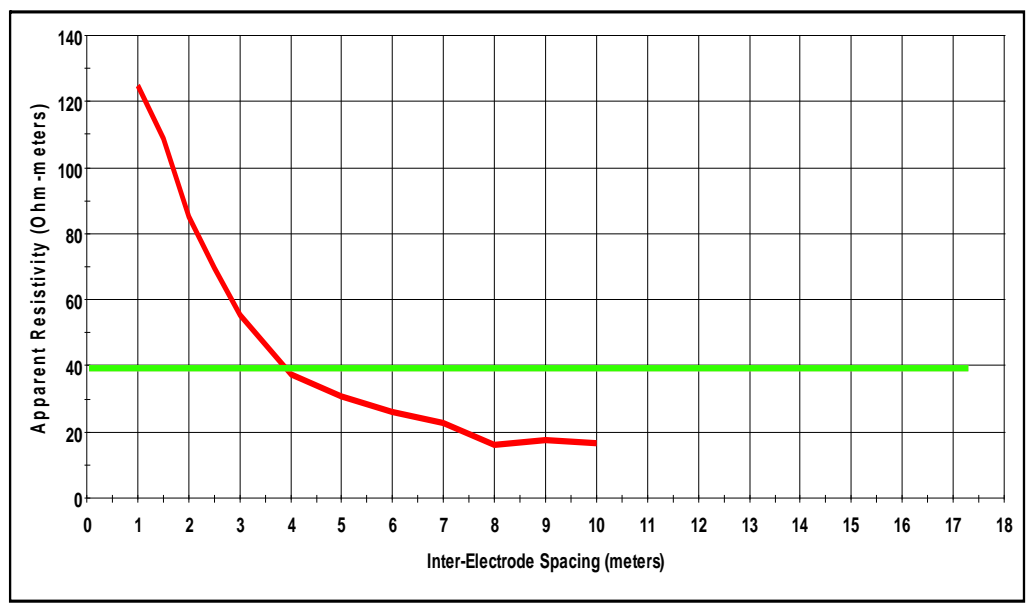

Figure 12. Simulation results of single-layer soil model

In this case according measurements using Wenner's method, the soil is modeled as a single layered, with the uniform soil resistivity of $\rho=39.425 \Omega \mathrm{m}$, which is obtained using REASP module. Deviation of theoretical apparent resistance from the measured apparent resistances is expressed by RMS-error (rootmean-squared error), RMS error between measured and calculated resistance in this case is $36.48 \%$, which is a significant error. This model is the easiest to use but not appropriate because of such huge error.

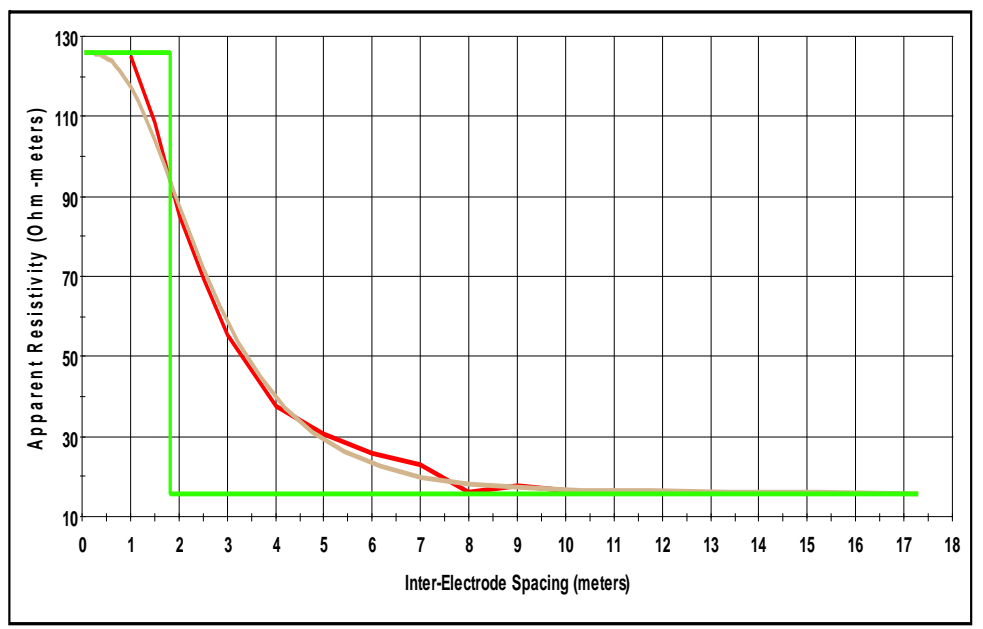

Figure 13. Simulation results of two-layered horizontal soil model from measured results

Table 2. Specific resistance and thickness in two-layer soil model

\begin{tabular}{ccc}
\hline $\begin{array}{c}\text { Number of the } \\
\text { layers }\end{array}$ & $\begin{array}{c}\text { Specific soil resistance } \\
\rho[\Omega \mathrm{m}]\end{array}$ & $\begin{array}{c}\text { Thickness of the } \\
\text { layer }[\mathrm{m}])\end{array}$ \\
\hline 1 & 126.0062 & 1.816445 \\
2 & 15.48484 & $\infty$ \\
\hline
\end{tabular}

In this case according measurements using Wenner's method, the soil is modeled with RESAP module as two layered model. RMS error when the soil is modeled as a two-layer is $7.44 \%$. Because of the RMS error value, it is obvious that two-layered model corresponds more to the model of the real soil on which measurements are performed than to the previous case of a single-layer soil model. When the threelayer model is used, RMS-error is $6.09 \%$. RMS error is smaller than in two-layer soil model. Three-layered model corresponds best to the model of the real soil on which measurements are performed. 


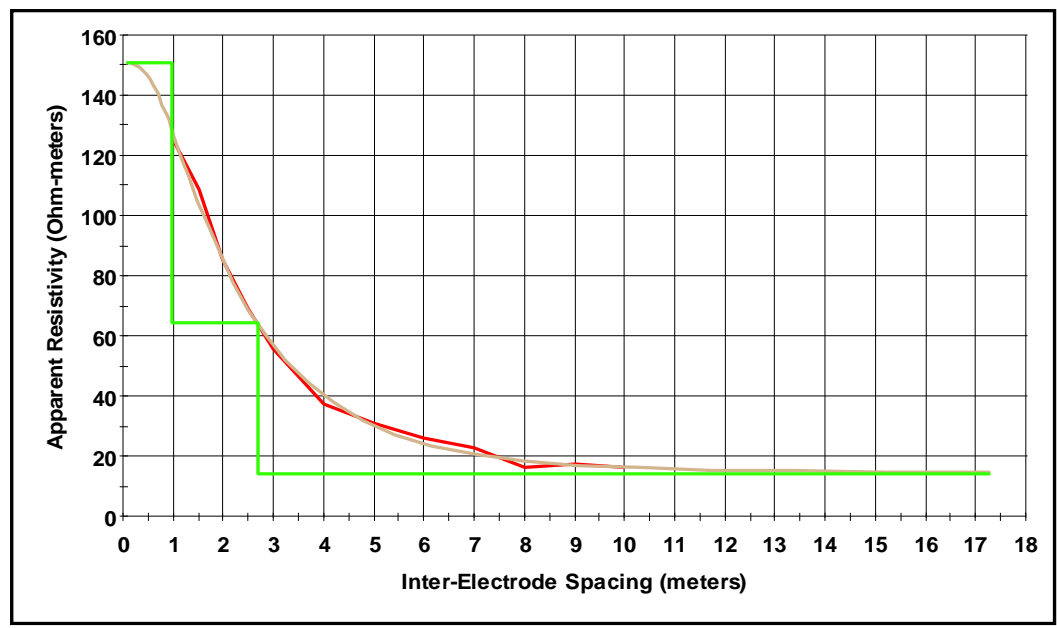

Figure 14. Simulation results of three-layered horizontal soil model from measured results

Table 3. Specific resistance and thickness in three-layer soil model

\begin{tabular}{ccc}
\hline $\begin{array}{c}\text { Number of the } \\
\text { layers }\end{array}$ & $\begin{array}{c}\text { Specific soil } \\
\text { resistance } \rho[\Omega \mathrm{m}]\end{array}$ & $\begin{array}{c}\text { Thickness of the } \\
\text { layer }[\mathrm{m}])\end{array}$ \\
\hline 1 & 150.8457 & 0.990462 \\
2 & 64.09731 & 1.694774 \\
3 & 14.05551 & $\infty$ \\
\hline
\end{tabular}

\section{SIMULATION RESULTS FOR SAMPLE CASE}

Grounding grid is placed at a depth of $0.8 \mathrm{~m}$. It is meshed grid made up of 12 transverse and 9 longitudinal grounding strips, which are connected to each other and form a network of overall $110 \times 80 \mathrm{~m}$. [12] The length of the Fe/ $\mathrm{Zn}$ conductors $30 \times 5 \mathrm{~mm}$ are $1950 \mathrm{~m}$. Additionally, on the connecting grounding grid 25 properly distributed grounding rods are placed in length of $3 \mathrm{~m}$. The diameter of rods is $50.8 \mathrm{~mm}$. The current that is injected into the grounding system is $\mathrm{Ik}=7480 \mathrm{~A}$.

The grounding grid from Figure 15 is buried in the depth of $0.8 \mathrm{~m}$ in a single-layer soil model obtained by simulating in Figure 12. Running the simulation provides the following report. Resistance of single-layered soil is $39.425 \Omega \mathrm{m}$. Resistance of the grounding grid is $\mathrm{Ri}=0.1867 \Omega$. The potential of the grounding grid is GPR $=1396.8 \mathrm{~V}$.

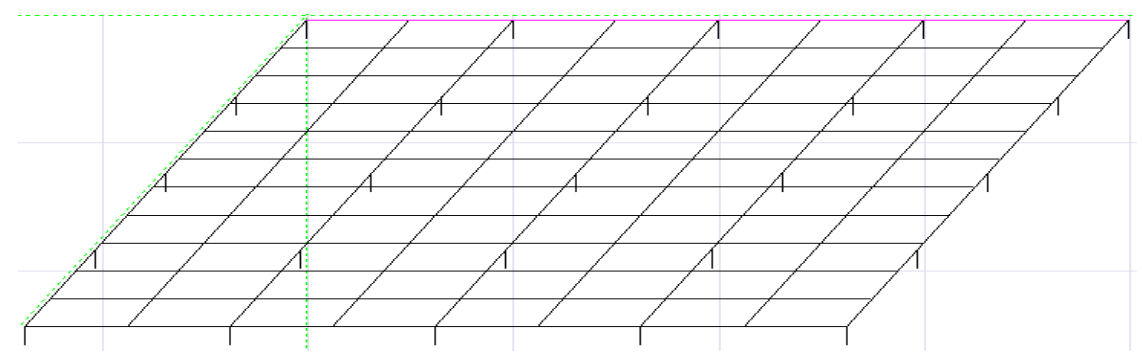

Figure 15. Model of the ground system used in simulation 


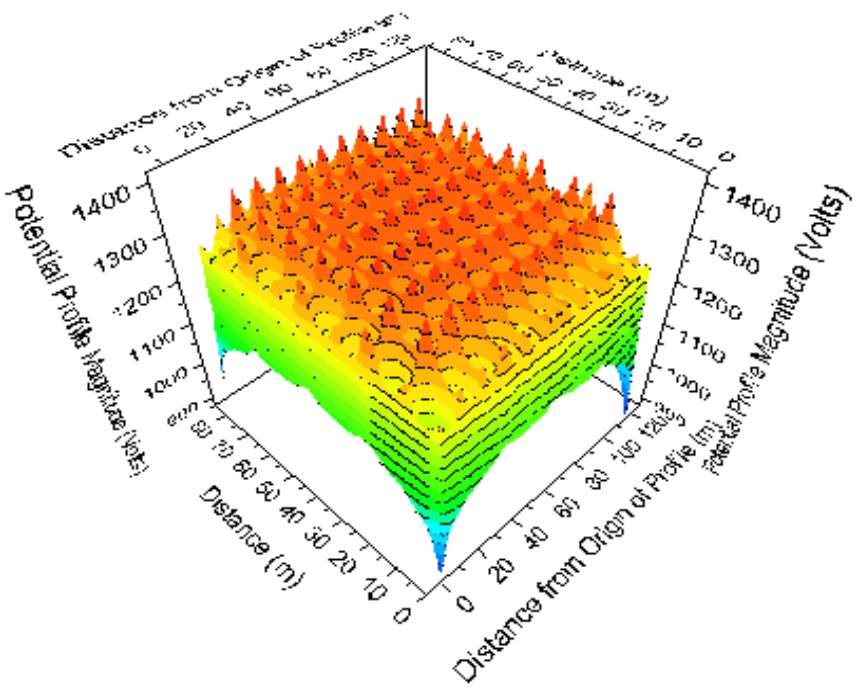

Figure 16. 3-D profile of GPR for a grid in a single-layer soil model

According to the selected standards 70KG-IEEE, the body weight of $70 \mathrm{~kg}$ and fibrillation current according C3-IEC, body resistance according IEC that is located on the surface can be exposed to the maximum touch voltage of $292.2 \mathrm{~V}$ and steps voltage of $358.2 \mathrm{~V}$ for the fault clearing time of $0.5 \mathrm{~s}$. In this case there is no additional surface layer on the soil.

From Figure 17 and Figure 18 in spite of relatively high GPR, touch and step voltages are in the permissible security limits. By placing the grounding grid to a depth of $0.8 \mathrm{~m}$ in the two-layer model of soil, obtained by simulation in Figure 13, the result will be a network composed of connecting ground strips in the first layer of greater resistance, while rods reach the second layer of lower resistance. Running the simulation provides the following report.

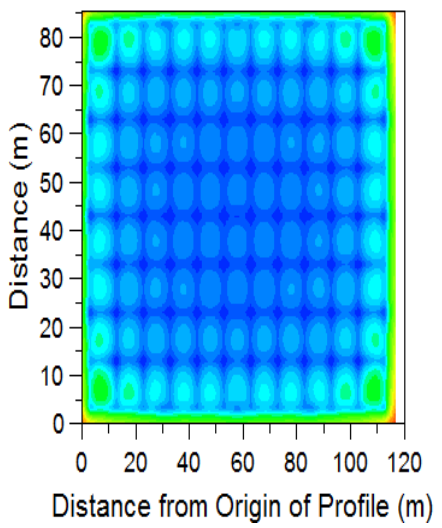

Figure 17. Touch voltage for single-layer model
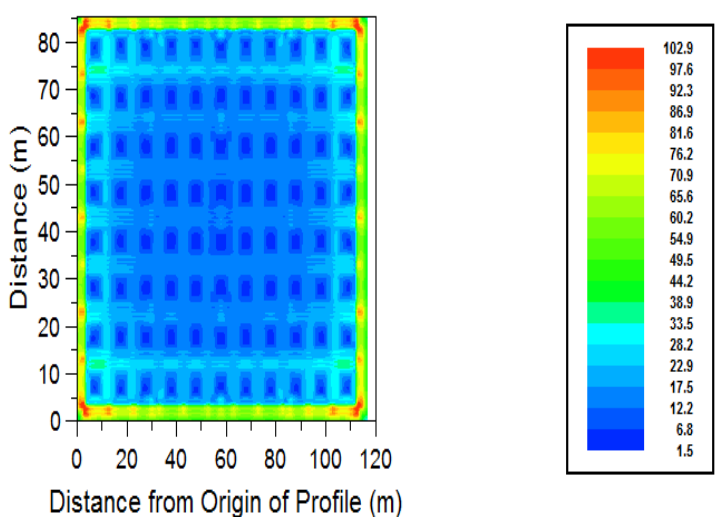

Figure 18. Step voltage for single-layer model 


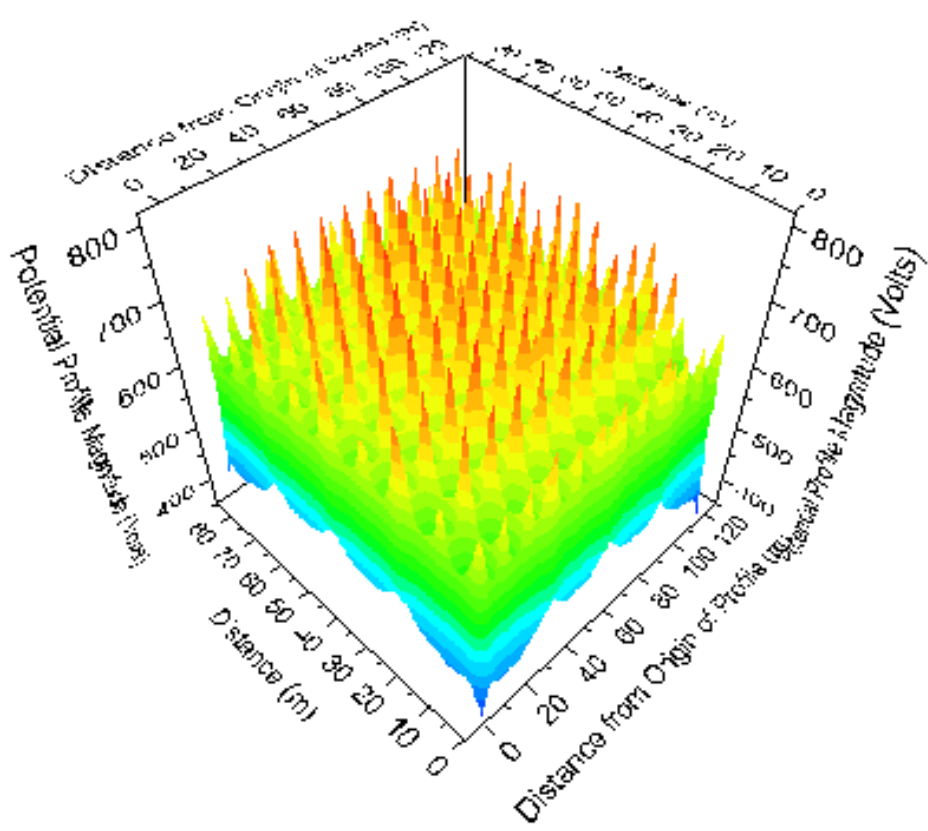

Figure 19. 3-D profile of GPR for a grid in two-layer soil model

The resistance of the first layer is $150.8457 \Omega \mathrm{m}$. Resistance of the second layer is $64.0973 \Omega \mathrm{m}$. Resistance of the third layer is $14.055 \Omega \mathrm{m}$ Thickness of the first layer is $0.99046 \mathrm{~m}$, thickness of the second layer is $1.694774 \mathrm{~m}$. Resistance the grounding grid is $\mathrm{Ri}=0.11294 \Omega$. The potential of the grounding grid $\mathrm{GPR}=844.76 \mathrm{~V}$. In the two-layer model of the soil, touch voltage and step voltage are slightly higher, but still in permissible limits since the amount of the maximum touch voltage is $340.5 \mathrm{~V}$ and step voltage is $551.5 \mathrm{~V}$ and are obtained from security threshold computation for fault clearing time of $0.5 \mathrm{~s}$.

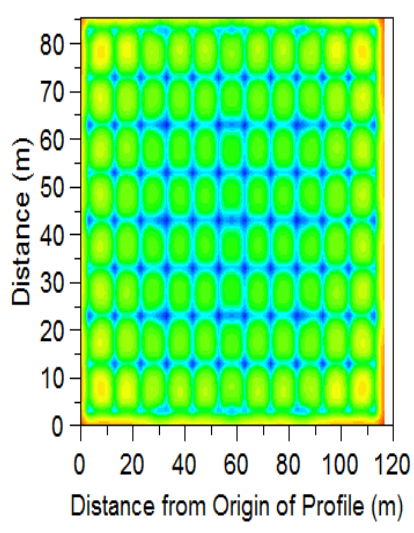

Figure 20. Touch voltage for two-layer model
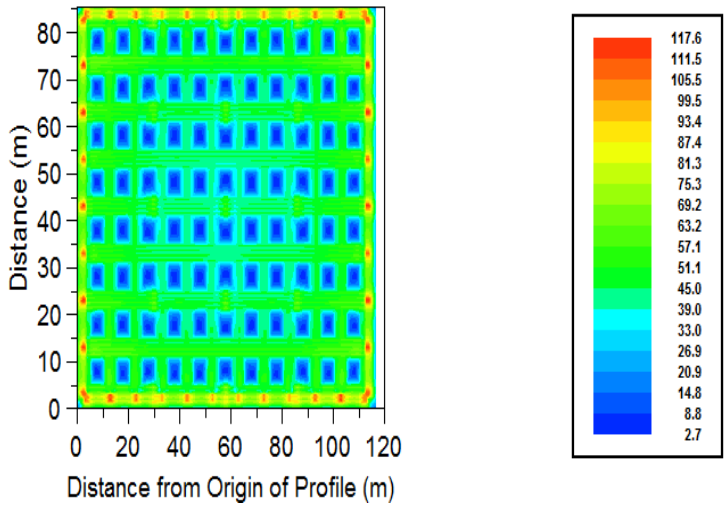

Figure 21. Step voltage for two-layer model

At the end, the grounding grid from Figure 15 is buried in the depth of $0.8 \mathrm{~m}$ in a three-layer soil model obtained by simulating in RESAP module. The resistance of the first layer is $126.0062 \Omega \mathrm{m}$. Resistance of the second layer is $64.0973 \Omega \mathrm{m}$. Resistance of the third layer is $15.4848 \Omega \mathrm{m}$. Thickness of the first layer is $0.99046 \mathrm{~m}$. Thickness of the second layer is $1.69477 \mathrm{~m}$. Resistance of the grounding grid is $\mathrm{Ri}=$ $0.11184 \Omega$. The potential of the grounding grid is $\mathrm{GPR}=836.55 \mathrm{~V}$. 


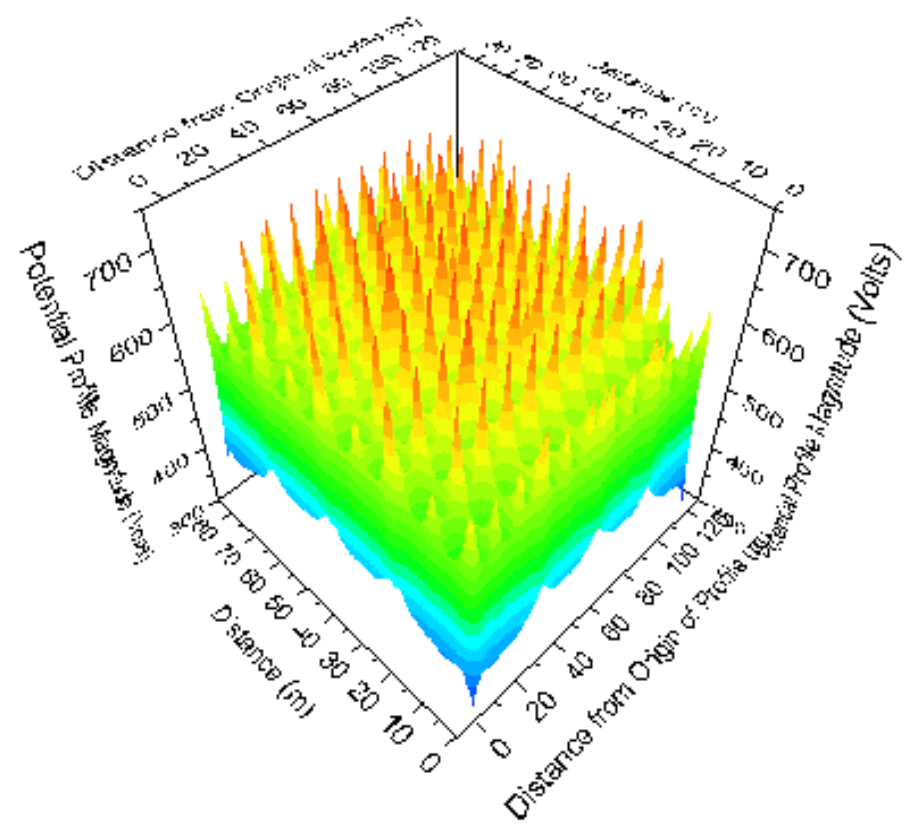

Figure 22. 3-D profile of GPR for a grid in three-layer soil model

In the three-layer model of the soil, touch voltage and step voltage are smaller, and are in permissible limits since the amount of the maximum touch voltage is $354.4 \mathrm{~V}$ and step voltage is $607.0 \mathrm{~V}$ and are obtained from security threshold computation for fault clearing time of $0.5 \mathrm{~s}$.

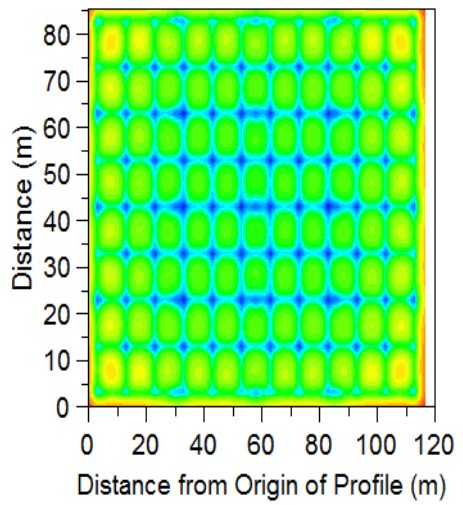

Figure 23. Touch voltage for three-layer model

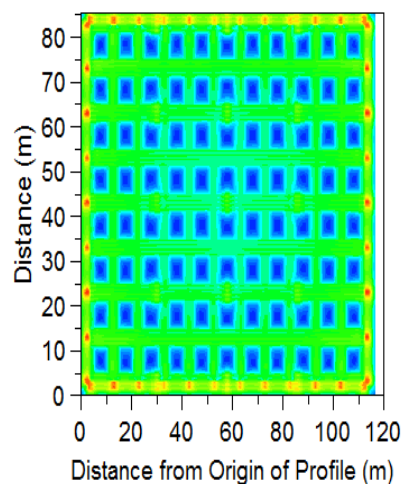

Figure 24. Step voltage for three-layer model

If the dangerous situation for personnel during the fault conditions over the grounding grid want to be avoided, usually isolation surface layer of crushed stone can be used [8],[9]. For that situation safety values for touch and step voltages are much higher. Touch permissible voltage is $673.9 \mathrm{~V}$ and step permissible voltage $1884.8 \mathrm{~V}$. 


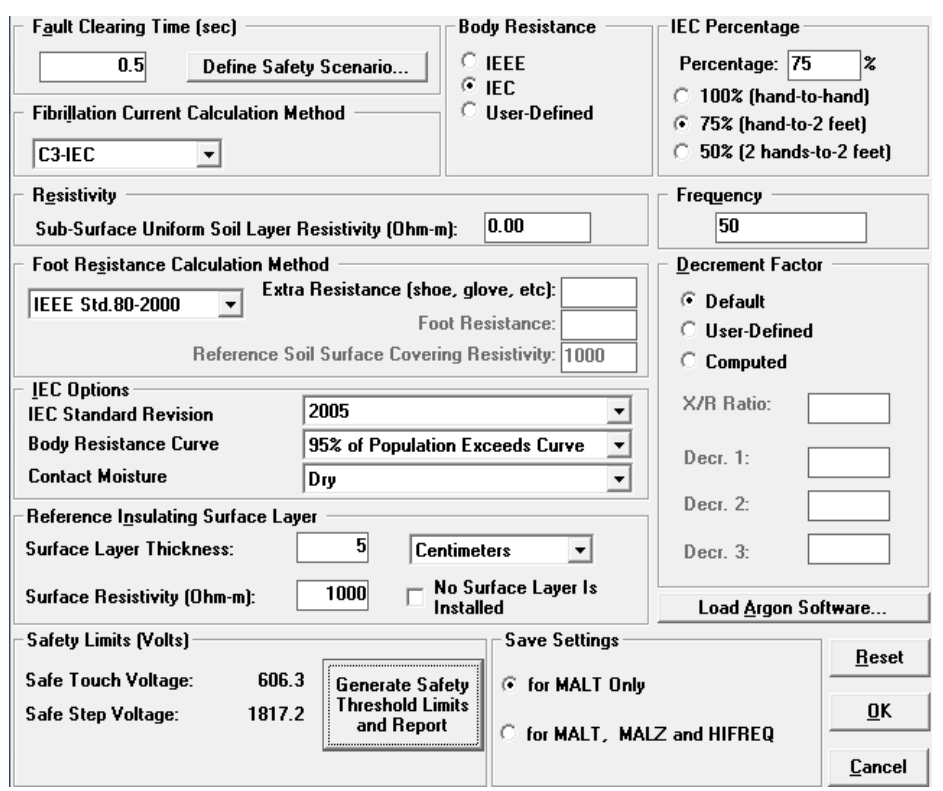

Figure 25. Safety Calculations Table

If the influence of vertical soil model and soil resistivity wants to be investigated on step and touch voltages next data are used according to the Figure 11.

Table 4. Specific resistance and thickness in vertical two-layer soil model

\begin{tabular}{cccccc}
\hline $\begin{array}{c}\text { Number of the } \\
\text { layers }\end{array}$ & $\begin{array}{c}\text { Specific soil } \\
\text { resistance } \rho[\Omega \mathrm{m}]\end{array}$ & $\begin{array}{c}\text { Thickness of } \\
\text { the layer }[\mathrm{m}]\end{array}$ & \multicolumn{3}{c}{ Coordinates } \\
\hline 1 & 126.0062 & $\infty$ & Angle $\theta$ & $\mathrm{Xp}$ & $\mathrm{Yp}$ \\
2 & 15.48484 & $\infty$ & $90^{\circ}$ & 95 & 85 \\
\hline
\end{tabular}

The main grid potential rise (GPR) is $1498.2 \mathrm{~V}$, because the most of grounding grid is in left higher resistivity soil. The asymmetry and the influence of vertical soil model on touch and step voltages cannot be clearly visible since grounding grid is on the same GPR.

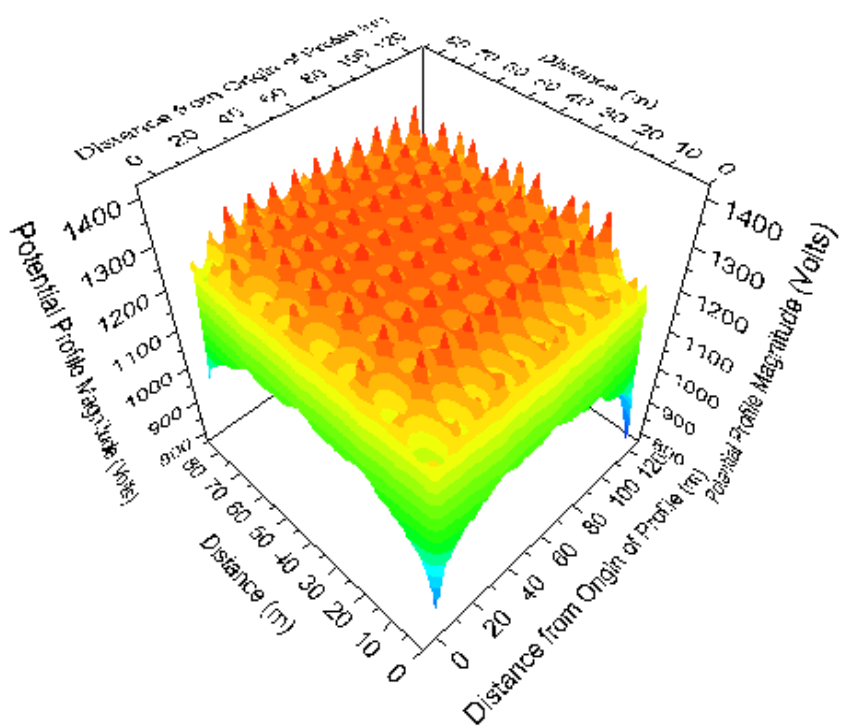

Figure 26. 3-D profile of GPR for a grid in vertical soil model 


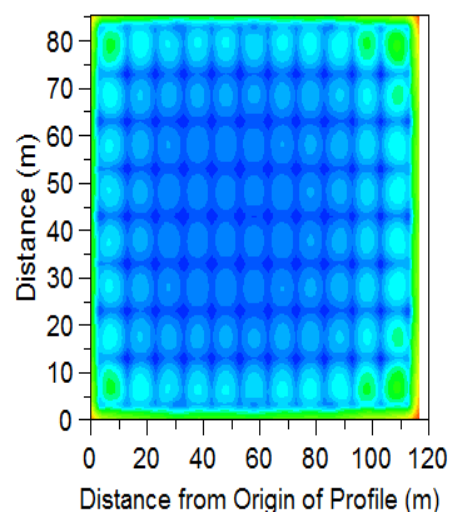

Figure 27. Touch voltage for two-layer vertical soil model
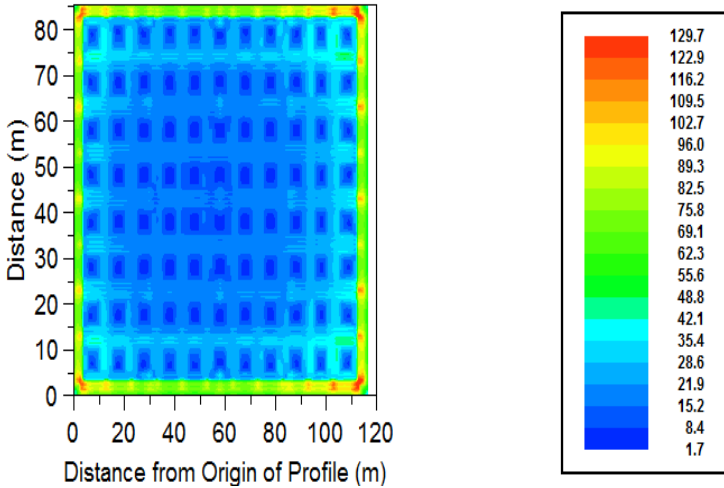

Figure 28. Step voltage for two-layer vertical soil model

Touch and step voltages in two-layer vertical soil model are higher since the most of grounding grid is buried in higher soil resistivity part $\rho_{1}$ and small asymmetry can be seen on $2 \mathrm{D}$ plots. The potentials along the vertical layer boundary must be continuous. Knowing that the soil potential is proportional to the product of its resistivity $(\rho)$ and the leakage current $(I)$, the condition $\rho_{I} * I_{I}=\rho_{2} * I_{2}$ must be valid at the interface between both vertical layers, where the subscripts 1 and 2 stand for each vertical soil layer. For the aim to examine the influence of the two layer vertical soil model with high difference in soil resistivity on touch and step voltage model next data are used (Table 5).

Table $\underline{\text { 5. Hypothetical specific resistance and thickness in vertical two-layer soil model }}$

\begin{tabular}{cccccc}
\hline $\begin{array}{c}\text { Number of the } \\
\text { layers }\end{array}$ & $\begin{array}{c}\text { Specific soil } \\
\text { resistance } \rho[\Omega \mathrm{m}]\end{array}$ & $\begin{array}{c}\text { Thickness of } \\
\text { the layer }[\mathrm{m}]\end{array}$ & \multicolumn{3}{c}{ Coordinates } \\
\hline 1 & 40000 & $\infty$ & Angle $\theta$ & Xp & Yp \\
2 & 40 & $\infty$ & $90^{\circ}$ & 95 & 85 \\
\hline
\end{tabular}

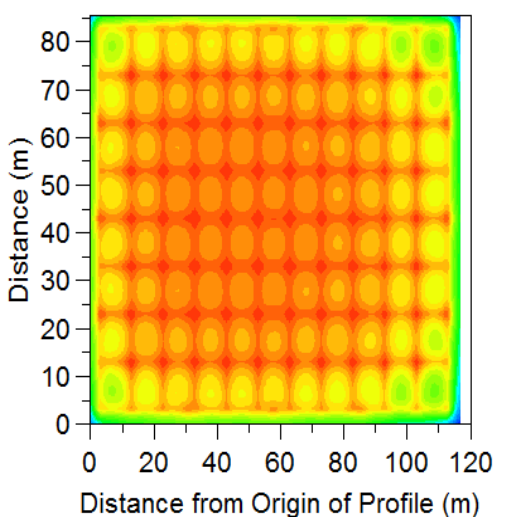

Figure 29. GPR for two-layer vertical model
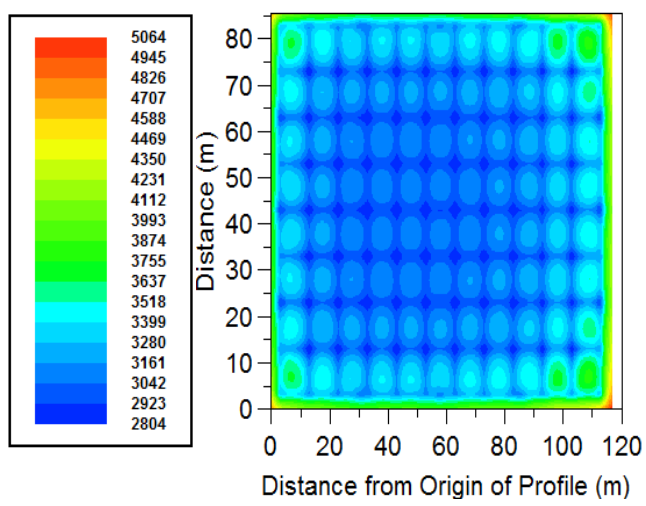

Figure 30. Touch voltage for two-layer vertical model

Since the potentials along the vertical layer boundary must be continuous, this explains why there are no sharp variations in the surface potentials from one vertical layer to the other, even in the case of a high resistivity contrast. However, if the spots on the above 2D plot are carefully looked at, it can be noticed that the potentials are not exactly symmetrical, which is actually a consequence of the used vertical soil structure.

If we compare 3-D profiles of potential grounding for the grounding grid in uniform soil model (Figure 16) and ground device in a two-layer soil model (Figure 19), and three-layer soil model (Figure 23), the first difference is evident in the amount of earth potential. When the soil is modeled as a single-layer, the grounding potential of the system (GPR) is $1396.8 \mathrm{~V}$, while in the case of the same grounding system placed in a two-layer soil model, the grounding potential is $844.76 \mathrm{~V}$ and in a three-layer soil model is $836.55 \mathrm{~V}$. 
The potential of the grounding device is equal for the entire grounding and all metal parts attached to it. As the GPR directly depends on the potential of the grounding grid and soil models in the case of a single-layer model of the soil, the maximum grounding potential is $\approx 1396 \mathrm{~V}$, and in the case of two-layer soil model, $\approx 844.7 \mathrm{~V}$. Therefore, in the two-layer soil model $60.5 \%$ less grounding potential is achieved in relation to the single layer model of soil. Difference between two-layer and three-layer model in GPR is minimal $\mathrm{GPR}_{\text {two-layer }}=1.009 \mathrm{GPR}_{\text {three-layer }}$. Such a difference between single-layer and two-layer results could have been expected because the model in a single-layer soil has a large RMS-error and the values of the potential of the grounding grid can be considered more accurate and closer to those expected in reality if two-layer or threelayer model is used.

Another difference is evident in the appearance of the 3-D profile of GPR. For a single-layer soil model 3-D profile of the grounding potential at the ground is more balanced and has less so called "spikes" (the place where the vertical Fe / Zn strips merge with each other to form a network). In the two-layer soil, 3D profile is not as uniform and "spikes" are much larger. This is because the rods that are connected to the network of the grounding grid reach a better conductive lower layer. In both cases, the maximum potential values of the land are in the area of the central part of the grounding device and they gradually decrease toward the ends. The same situation is with a three-layer soil model.

If we compare the prospects of 2-D profile of a touch voltage (the difference between the potential of the grounding grid and potential of the earth) for the grounding grid in one single-layer model of the soil (Figure 17), and the grounding device in a two-layer model of the soil (Figure 18) and three-layer soil model (Figure 23), the "bellies" in the case of two-layer soil model are more visible. This is because of the aforementioned large "spikes" and irregularly shaped potential of grounding that causes somewhat greater potential difference, or touch voltages. The reason that the amount of touch voltages in both cases on the area of the grounding device will not exceed the safety limit is because the grounding device is oversized, a safety factor is further increased by filling the surface $5 \mathrm{~cm}$ by soil resistivity material resistance of $1000 \Omega \mathrm{m}$ (gravel). Problematic values appear just outside the grounding device but this is resolved in such a way that around the area where the device is buried, a fence is put in order to prevent access and possibly exposure to hazardous touch voltage. The fence must have its own grounding and should not be connected to the existing device because in this way the potential would be displayed on the area where the potential of the earth is low which would cause dangerous touch and step voltages.

Step voltages in the case of all three models (Figure 18, Figure 21 and Figure 24), are far below the value that would be considered dangerous, obtained according to the security settings, even outside the areas where grounding system is buried.

\section{CONCLUSION}

Modeling of soil based on the measurements of specific soil resistivity is left to the decision of that person who is in charge of it and on the basis of his assessment and experience, because there are no clearly defined rules for this area in Croatia. In practice, when modeling soil for grounding of electric power plants (substations), two-layer soil model proved to be good enough. With a single-layer model of the soil, the soil will be modeled well very rarely, as evidenced by simulations in this paper. Two-layer model may not be the rule by which to model the soil when grounding substation, and we must consider the possibility of modeling the soil as multi-layered depending on the estimation. Three-layer soul model do not effect so much in accuracy and safety so if it is not needed it could be avoided.

For the vertical soil model can be concluded that the last results show small asymmetrical potentials, even with a very high resistivity contrast. In light of the above results, it seems that the asymmetry of the system has a greater impact on the asymmetry of the potentials than the resistivity difference between the vertical layers. Incorrect soil modeling leads to a relatively large difference in all important parameters in the grounding systems, as it is shown in this paper. As the modeling of soil is considered a complex task, it is recommended to use computers and computer software made for this purpose, as this will avoid additional errors resulting from the use of approximate graphical and analytical methods.

\section{ACKNOWLEDGEMENTS}

We would like to thank Marc-Andre Joyal, PhD from SES Technologies Ltd. Canada, for his help and valuable comment during the computations and simulations. 


\section{REFERENCES}

[1] IEEE, "Guide for Measuring Earth Resistivity, Ground Impedance, and Earth Surface Potentials of a Ground System," The Institute of Electrical and Electronics Engineers, Inc., New York, 1983.

[2] IEEE, "Guide for Safety in AC Substation Grounding," The Institute of Electrical and Electronic Engineers, Inc., New York, 2000.

[3] IEEE, "Guide for Measuring Earth Resistivity, Ground Impedance, and Earth Surface Potentials of a Ground System," The Institute of Electrical and Electronics Engineers, Inc., New York, 1983.

[4] CDEGS software, "User Manual," 2016.

[5] M. Mokhtari, et al., "Integration of Frequency Dependent Soil Electrical Properties in Grounding Electrode Circuit Mode," International Journal of Electrical and Computer Engineering (IJECE), vol/issue: 6(2), 2016.

[6] E. Mombello, et al., "Two-layer soil model for power station grounding system calculation considering multylayer soil stratification," Electric Power Systems Research, vol. 37, pp. 67-78, 1996.

[7] J. Liu and F. P. Dawalibi, "Detailed Parametric Analysis of Grounding System Performance in Two-Layer Soil Structures," Proceedings of the Seventh IASTED International Conference on Power and Energy Systems, Clearwater Beach, USA, Nov.r 28 - Dec. 1, pp. 370-375, 2004.

[8] J. Ma, et al., "On the equivalence of uniform and two-layer soils to multilayer soils in the analysis of grounding systems," IEE Proceedings-Generation, Transmission and Distribution, vol. 143, pp. 49-55, 1996.

[9] H. S. Lee, et al., "Efficient Ground Grid Designs in Uniform and Two-Layer Soils," Korean IEE Transactions, 1997.

[10] J. He, et al., "Methodology and technology for power system grounding," John Wiley \& Sons, Singapore, 2013.

[11] R. Ibsaim and A. Ammar, "Performance assessment and modeling of grounding grid, Case study of Alkhom 400 kV substation," University Bulletin, vol/issue: 1(16), 2014.

[12] D. Dostal, "Different sol models on transformer station $110710 \mathrm{Kv}$ atation grounding system graduate work," Faculty of electricak engineering Osijek, 2018

\section{BIOGRAPHIES OF AUTHORS}

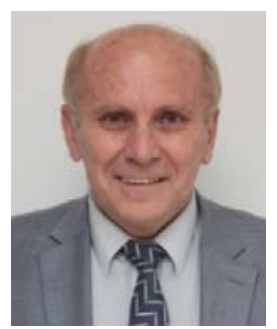

Srete Nikolovski, PhD (IEEE M'1995, SM'2005) was born in Belgrade on October 1, 1954. He obtained his BSc degree (1978) and MSc degree (1989) in Electrical Engineering at the Faculty of Electrical Engineering, University of Belgrade and his PhD degree (1993) at the Faculty of Electrical and Computing Engineering, University of Zagreb, Croatia. He is a Full Professor at the Department of Power Engineering at the Faculty of Electrical Engineering, University of Osijek, Croatia. His main interests are power system protection, power system modeling, simulation and reliability. He has published 180 academic papers in journals and international conferences proceedings. He is IEEE Senior member of Reliability Society and PES Society.

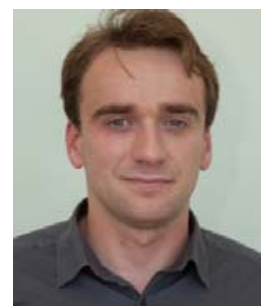

Goran Knežević, $\mathrm{PhD}$, was born on September 1, 1984. He obtained his diploma degree in 2007 and PhD degree in 2013 from the Faculty of Electrical Engineering, J.J. Strossmayer University of Osijek, Croatia. He currently works as an Assistant Professor at the Department of Power Engineering at the Faculty of Electrical Engineering Osijek. His topics of research include electricity markets simulation, energy markets integration, power system economics and cost/benefit assessment, optimization of power system operation and power system analysis.

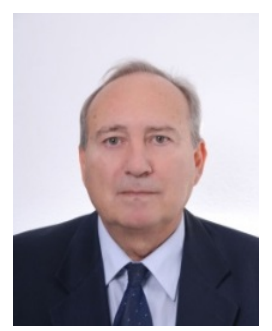

Baus Zoran, (PhD), was born in Pozarevac on June 15, 1951. He obtained his BSc degree (1975), MSc degree (1987), in Electrical engineering and his PhD degree from the Faculty of Electrical and Computing Engineering, Zagreb, Croatia in 2004. His major fields of interest include intelligent control, fuzzy control and optimization and power system analyses. Currently he is a Full professsor at Power Engineering Department at Faculty of Electrical Engineering, J.J. Strossmayer University in Osijek, Croatia. 